\title{
Spred2 inhibits epithelial-mesenchymal transition of colorectal cancer cells by impairing ERK signaling
}

\author{
HAO WANG ${ }^{1,2^{*}}$, SHUCHEN LIU $^{1 *}$, FANXUAN KONG $^{1,2}$, FENGJUN XIAO $^{1,2}$, YUXIANG LI $^{1,2}$, \\ HUA WANG ${ }^{1,2}$, SHUN ZHANG $^{3}$, DANDAN HUANG ${ }^{3}$, LISHENG WANG ${ }^{1,2,4}$ and YUEFENG YANG ${ }^{1-3}$ \\ ${ }^{1}$ Beijing Institute of Radiation Medicine; ${ }^{2}$ Beijing Key Laboratory for Radiobiology, \\ Beijing Institute of Radiation Medicine, Beijing 100850; ${ }^{3}$ Department of Experimental \\ Medical Science and Key Laboratory of Diagnosis and Treatment of Digestive System Tumors of Zhejiang Province, \\ HwaMei Hospital, University of Chinese Academy of Sciences, Ningbo, Zhejiang 315000; \\ ${ }^{4}$ Department of Laboratory of Molecular Diagnosis and Regenerative Medicine, \\ Affiliated Hospital of Qingdao University, Qingdao, Shandong 266000, P.R. China
}

Received November 9, 2019; Accepted March 16, 2020

DOI: 10.3892/or.2020.7586

\begin{abstract}
Downregulation of the sprouty-related EVH1 domain protein 2 (Spred2) is closely associated with highly metastatic phenotypes in various tumors. However, the roles of Spred2 in the development and progression of colorectal cancer (CRC) are still largely unexplored. As anticipated, Spred2 expression was significantly downregulated in clinical tumor tissues. To restore Spred2 levels, Ad.Spred2, an adenoviral vector expressing Spred2, was transduced into CRC cells. It was revealed that Ad.Spred 2 inhibited the proliferation and decreased the survival and migration of SW480 cells. Epithelial-mesenchymal transition (EMT) is an essential event during tumor metastasis to distant sites. It was revealed that Ad.Spred 2 markedly inhibited EMT by promoting F-actin reorganization, upregulating E-cadherin levels and reducing vimentin protein expression. Notably, extracellular-regulated kinase (ERK) signaling inhibition by PD98059 induced similar effects on EMT in CRC cells, indicating that Ad.Spred 2 regulated EMT in CRC cells in an ERK-dependent manner. Transforming growth factor $\beta$ (TGF- $\beta$ ), a well-known inducer of EMT, increased E-cadherin expression, decreased vimentin expression and promoted migration in CRC cells. However, neither Ad.Spred2 nor
\end{abstract}

Correspondence to: Dr Yuefeng Yang or Dr Lisheng Wang, Beijing Institute of Radiation Medicine, 27 Taiping Road, Haidian, Beijing 100850, P.R. China

E-mail: yuefengyang1981@163.com

E-mail: lishengwang@ymail.com

${ }^{*}$ Contributed equally

Key words: sprouty-related EVH1 domain protein 2, epithelial-mesenchymal transition, migration, transforming growth factor $\beta$, extracellular-regulated kinase, SMADs
PD98059 had an obvious effect on the expression of SMAD2/3 or SMAD4 in SW480 cells, indicating that Ad.Spred 2 inhibited EMT in a SMAD-independent manner. Notably, Ad.Spred2 transduction downregulated SAMD2/3 and SMAD4 levels in HCT116 cells in an ERK-independent manner. It was speculated that Ad.Spred2 inhibited the EMT of HCT116 cells by both blocking ERK signaling and reducing SMAD signaling. It was concluded that Spred2 inhibited EMT in CRC cells by interfering with ERK signaling, with or without reduced SMAD signaling. Therefore, the introduction of the clinical application of Spred 2 has great potential for development as a gene therapy approach for CRC.

\section{Introduction}

Colorectal cancer (CRC), the fourth leading cause of cancer-related deaths worldwide, resulted in 50,630 deaths in 2018 in the United States $(1,2)$. With the improvement of screening technologies and therapeutic strategies, the death rate from $\mathrm{CRC}$ has been dropping over the past decades $(3,4)$. However, reduced sensitivity to conventional treatments, such as chemotherapy and radiotherapy, is a major obstacle in the treatment of advanced and metastatic CRC $(5,6)$. Therefore, it is urgent to develop novel effective therapeutic strategies.

It has been widely demonstrated that aberrant activation of the Ras/Raf-1/extracellular-regulated kinase (ERK) signaling pathway plays pivotal roles in the initiation and progression of various tumors (7-10). Spred2 is an important member of the sprouty-related EVH1 domain proteins, which are known to be negative regulators of growth factor-induced Ras/Raf-1/ERK activation $(11,12)$. As anticipated, Spred 2 was revealed to be significantly downregulated in various tumor cells, including hematological malignancies and solid tumors $(13,14)$. Moreover, the Spred 2 expression level was demonstrated to be closely associated with distal metastasis and survival in the clinic $(15,16)$. Notably, strategies to increase Spred2 expression would be beneficial to enhance antitumor responses. For example, our group reported that imatinib could upregulate 
Spred2, and induce apoptosis and growth arrest in chronic myeloid leukemia (CML) cells (17). However, the roles of Spred 2 in CRC are still unexplored.

In the present study, whether Spred 2 expression is obviously decreased in the tumor tissues of CRC patients was first explored. Then, a fiber-modified replication-deficient adenoviral vector expressing Spred2, Ad.Spred2, was prepared as reported previously (17). Ad.Spred 2 mediated Spred 2 overexpression in CRC cells inhibited cellular proliferation, survival and migration, and reduced epithelial-mesenchymal transition (EMT). Finally, it was revealed that Spred2 inhibited EMT in CRC cells by blocking the ERK signaling pathway, with or without reduced TGF $\beta / \mathrm{SMAD}$ signaling.

\section{Materials and methods}

Spred 2 mRNA expression in tumor tissues from CRC patients. Surgical specimens were obtained from 26 CRC patients, including 11 male and 15 female patients from 49 to 86 years old, that underwent clinical pathological examination at Beijing Friendship Hospital, an affiliate of Capital Medical University, from August 2010 to December 2013. Beijing Friendship Hospital is our cooperative partner in the field of cancer research. All patients provided written consent and all the procedures were approved by the Ethics Committee of Beijing Friendship Hospital. The mRNA expression of Spred2, in tumor tissues and distal normal tissues, was analyzed by real-time reverse transcription polymerase chain reaction (RT-PCR).

Cell lines. The SW480, SW620, RKO and Colo205 and HCT116 human CRC cell lines were purchased from the cell bank at the Shanghai Institutes for Biological Sciences, Chinese Academy of Sciences. Human embryonic kidney cell line, 293, was obtained from American Type Culture Collection (ATCC). SW480, SW620, Colo205 and HCT116 cells were maintained in RPMI-1640 medium (Gibco; Thermo Fisher Scientific, Inc.) supplemented with $10 \%$ fetal calf serum (FCS), while 293 cells were cultured in Dulbecco's minimal essential medium (DMEM; Gibco; Thermo Fisher Scientific, Inc.) plus $10 \%$ FCS. The RKO cells were maintained in Eagle's Minimum Essential Medium (EMEM; Gibco; Thermo Fisher Scientific, Inc.) containing $10 \%$ FCS.

Adenoviruses. An adenoviral vector expressing Spred2, Ad.Spred2, was constructed and prepared using a fiber modified Ad5/F11p adenoviral system as described previously (18). In addition, an Ad5/F11p adenoviral system-based adenoviral vector without any transgene, Ad.Null was prepared and used as a control. All the adenoviruses were purified by $\mathrm{CsCl}$ density gradient centrifugation, and the infectious titers were measured by median tissue culture infective dose $\left(\mathrm{TCID}_{50}\right)$.

\section{Analysis of biological characteristics}

Proliferation. Exponentially growing SW480 CRC cells were labeled with the dye eFluor ${ }^{\circledR} 670$ (eBioscience; Thermo Fisher Scientific, Inc.) according to the manufacturers' instructions. Then, the labeled cells were seeded into 12 -well plates at a density of $1 \times 10^{5}$ cells/well. Four hours later, the cells were infected with Ad.Spred 2 or Ad.Null at a multiplicity of infection (MOI) of 50. At 0, 24, 48, 72 and $96 \mathrm{~h}$ after infection, the cells were collected. The fluorescence intensity of the eFluor 670 dye was detected by flow cytometry, and the proliferation index was calculated.

Apoptosis. Exponentially growing SW480 cells were plated into a 6 -well plate at a density of $5.0 \times 10^{5}$ cells/well. Twenty-four hours later, the cells were infected with Ad.Spred2 or Ad.Null at an MOI of 50. After $4 \mathrm{~h}$ of incubation, the culture media were replaced with fresh RPMI-1640 medium plus 10\% FCS. At 24 and $48 \mathrm{~h}$ after infection, the cells were collected, labeled with APC conjugated Annexin-V and PI (Sungene Biotech Co., Ltd.), and analyzed by flow cytometry using CellQuest Pro software version 5.1 (FACSCalibur; BD Biosciences).

Migration assay. For the wound healing assay, exponentially growing SW480 cells were seeded in a 6-well plate at a density of $5.0 \times 10^{5}$ cells/well. Twenty-four hours later, the cells were infected by Ad.Spred 2 or Ad.Null at an MOI of 50 , or treated with $10 \mathrm{ng} / \mathrm{ml}$ recombinant human TGF- $\beta$ (PeproTech, Inc.). After another $24 \mathrm{~h}$ of incubation, confluent cells were scratched to generate wounds. At 0 and $24 \mathrm{~h}$ after the scratch, live cell images (x100) were obtained at indicated positions using an inverted microscope and charge-coupled device (Olympus Corporation). The distances between the two margins of the wounds were measured, and the percentage of wound healing was calculated as previously described (19).

For the Transwell assay, exponentially growing SW480 cells were infected with Ad.Spred2 or Ad.Null at an MOI of 50. Twenty-four hours later, the cells were collected and resuspended in FCS-free RPMI-1640 medium at a density of $5.0 \times 10^{5}$ cells $/ \mathrm{ml}$. Then, a Transwell insert was added to the well by inserting the bottom of the insert into the medium (RPMI-1640 medium plus 2\% FCS) in the lower compartment. Then, $200 \mu \mathrm{l}$ of cells was added to the Transwell insert. After $8 \mathrm{~h}$ of incubation, the migrated cells were fixed by $800 \mu \mathrm{l}$ methanol for $30 \mathrm{~min}$ and stained with $0.1 \%$ crystal violet for $20 \mathrm{~min}$ at room temperature. The cells were observed by inverted microscope and counted in 5 randomly selected views using a magnification of $\mathrm{x} 100$.

Giemsa staining. Exponentially growing SW480 cells were seeded into 6-well plates at a density of $5 \times 10^{5}$ cells/well. Twenty-four hours later, $10 \mathrm{ng} / \mathrm{ml}$ TGF- $\beta$ was added and incubation continued for another $48 \mathrm{~h}$. Cells were stained with Giemsa staining buffer (Beijing Solarbio Science \& Technology Co., Ltd.) for 15-30 min at room temperature. Cell images were obtained by inverted microscope and charge-coupled device using a magnification of $\mathrm{x} 400$.

Rhodamine-phalloidin staining. A total of $1 \times 10^{5}$ exponentially growing SW480 cells and HCT116 cells were seeded into a 35-mm cell culture dish with a glass bottom. Twenty-four hours later, the cells were treated with Ad.Spred2, Ad.Null, or $10 \mathrm{ng} / \mathrm{ml} \mathrm{TGF}-\beta$. After another $48 \mathrm{~h}$ of incubation, the cells were stained with rhodamine-phalloidin for $1 \mathrm{~h}$ at room temperature (Thermo Fisher Scientific, Inc.) according to the manufacturers' instructions. The results were analyzed by confocal microscopy (Perkin Elmer). 
Immunofluorescence. Exponentially growing SW480 cells were plated on a $35-\mathrm{mm}$ cell culture dish as aforementioned. Twenty-four hours later, the cells were infected with Ad.Spred 2 or Ad.Null at a MOI of 50, or treated by $10 \mathrm{ng} / \mathrm{ml}$ TGF- $\beta$. Forty-eight hours later, the expression of E-cadherin, $\mathrm{N}$-cadherin and vimentin was analyzed by immunofluorescence. Briefly, cells were incubated with rabbit anti-human E-cadherin antibody (product code ab40772), rabbit anti-human N-cadherin antibody (product code ab18203) or mouse anti-human vimentin antibody (product code ab20346) (all from Abcam) with a dilution of $1: 500$ at $4^{\circ} \mathrm{C}$ overnight. The following day, corresponding secondary antibodies, including FITC-conjugated goat anti-rabbit IgG H\&L (cat. no. ZF0311) and goat anti-mouse IgG H\&L (cat. no. ZF0312) (ZSGB-Bio; OriGene Technologies, Inc.), or TRITC conjugated goat anti-rabbit IgG H\&L (cat. no. BA1090) and goat anti-mouse IgG H\&L (cat. no. BA1089) (Boster Biological Technology, Ltd.) were added at a dilution of 1:2,000 and incubated for $1 \mathrm{~h}$ at room temperature. The results were observed by confocal microscopy.

Western blotting. Twenty-four and forty-eight hours after infection with Ad.Spred2 and Ad.Null, SW480 and HCT116 cells were collected and the protein was extracted by direct lysis buffer (DLB; Beijing Yangguang Yingrui Biotech, Inc.). At the indicated time-points, the expression of Spred2, ERK, phosphorylated ERK (p-ERK), E-cadherin, $\mathrm{N}$-cadherin, vimentin, SMAD2/3, phosphorylated SMAD2/3 (p-SMAD2/3) and SMAD4 was analyzed by western-blotting using rabbit anti-human Spred2 antibody (cat. no. PRS4849) (Sigma-Aldrich; Merck KGaA), rabbit anti-MAPK/ERK antibody (cat. no. 4695), rabbit anti-phospho-Erk1/2 (Thr202/Tyr204) antibody (cat. no. 4370) (all from Cell Signaling Technology Inc.), rabbit anti-human E-cadherin antibody (product code ab40772), rabbit anti-human N-cadherin antibody (product code ab18203), mouse anti-human vimentin antibody (product code ab20346) (all from Abcam), rabbit anti-Slug antibody (cat. no. 9585), rabbit anti-Snail antibody (cat. no. 3879), rabbit anti-SMAD2/3 antibody (cat. no. 8685), rabbit anti-phospho-Smad2 (Ser465/467)/Smad3 (Ser423/425) antibody (cat. no. 8828) and rabbit anti-SMAD4 antibody (cat. no. 9515) (all from Cell Signaling Technology Inc.), respectively. Briefly, the concentration of total proteins was determined using Bicinchoninic Acid (BCA) method. Then, $40 \mu \mathrm{g}$ total proteins were loaded and separated by $10-15 \%$ SDS-polyacrylamide gel. After electroblotting onto a polyvinylidene difluoride membrane (EMD Millipore), the proteins were blocked by Tris-buffered saline containing $7.5 \%$ non-fat dry milk for $1 \mathrm{~h}$ at room temperature and labeled by corresponding primary antibodies at a dilution of 1:500 for $2 \mathrm{~h}$ at room temperature. Then, the membrane was incubated with corresponding horseradish peroxidase (HRP)-conjugated goat anti-rabbit antibody (cat. no. ZDR-5306) and HRP-conjugated goat anti-mouse antibody (cat. no. ZDR-5307) (ZSGB-Bio; OriGene Technologies, Inc.) at a dilution of 1:5,000. Then, the polyvinylidene difluoride membrane was visualized by using an ECL Plus Western Blotting Substrate (Pierce; Thermo Fisher Scientific, Inc.) and scanned by MultiImage II system (Alpha Innotech). The densitometry was analyzed by AlphaEase ${ }^{\circledR}$ Image Analysis software version 4.0 (Alpha Innotech). The relative expression of each indicated protein was normalized to GAPDH expression.

Real-time RT-PCR. Total RNA was isolated from tumor samples, corresponding normal tissues, and adenoviral vector-transfected SW480 cells. Then, cDNA was synthesized using RevertAid First Strand cDNA Synthesis Kit (Thermo Fisher Scientific, Inc.). The mRNA expression of Spred1 and Spred2 was quantified using SYBR ${ }^{\circledR}$ Premix Ex Taq ${ }^{\mathrm{TM}}$ (Tli RNaseH Plus) (Takara Bio, Inc.) on a 7500 Fast real-time PCR system (Applied Biosystems/Life Technologies; Thermo Fisher Scientific, Inc.). The optimal thermocycling conditions included: Pre-denaturation at $95^{\circ} \mathrm{C}$ for $2 \mathrm{~min}$; denaturation at $95^{\circ} \mathrm{C}$ for $30 \mathrm{sec}$, then annealing and extension at $60^{\circ} \mathrm{C}$ for $1 \mathrm{~min}$, repeated for 40 cycles. The relative expression levels were calculated by the $2^{-\Delta \Delta \mathrm{Cq}}$ method, using $\beta$-actin as the control (20). The following primers were used, Spred1 sense, 5'-ggaagcactagaaactggcattatt-3' and antisense, 5'-cacctggctg ctaggcaaac-3'; Spred2 sense, 5'-ctcatccatggtgaacgacagaa-3' and antisense, $5^{\prime}$-tgtcaaaggctcgggcatc-3'; and $\beta$-actin sense, 5'-gggacctgactgactacctc-3' and antisense, 5'-cttaatgtcacgcac gattt-3'.

Statistical analysis. Data are presented as the mean \pm SEM and were statistically analyzed by using GraphPad Prism software version 5 (GraphPad Software, Inc.). Paired t-tests were used to analyze Spred2 and Spred1 expression in the tumor tissues of CRC patients, and unpaired t-tests were used to analyze differences in other data between two groups. One-way analysis of variance (ANOVA) followed by the Bonferroni's post hoc test was performed to analyze multiple groups. Differences were considered statistically significant with a two-sided $\mathrm{P}<0.05$.

\section{Results}

Spred 2 inhibits the growth and migration of CRC cells, but promotes cellular apoptosis. Spred1 and Spred2, two important members of the Spred family, were revealed to be frequently downregulated in various cancers, such as hepatocellular carcinoma and prostate cancer $(9,13)$. In the present study, Spred1 and Spred2 expression in the tumor tissues of CRC patients were analyzed. The expression of Spred2, but not Spred1, was significantly downregulated in tumor tissues, compared to corresponding distal normal tissues (Fig. 1A and B). Moreover, it was also demonstrated that Spred 2 mRNA expression was decreased in CRC cell lines, compared to normal tissues (Fig. 1C). These results indicated that Spred2 plays pivotal roles in regulating tumor initiation and progression.

To investigate the roles and mechanisms of Spred2 in regulating the biological characteristics of CRC cells, a fiber-modified adenoviral vector expressing Spred2, Ad.Spred2, was prepared. Colon cancer cell lines, including SW480 cells, transfected with Ad.Spred 2 effectively expressed Spred2 (Fig. 2A and B). In SW480 cells, Spred2 overexpression inhibited proliferation and promoted cellular apoptosis (Fig. 2C and D). Moreover, Spred2 expression also significantly 

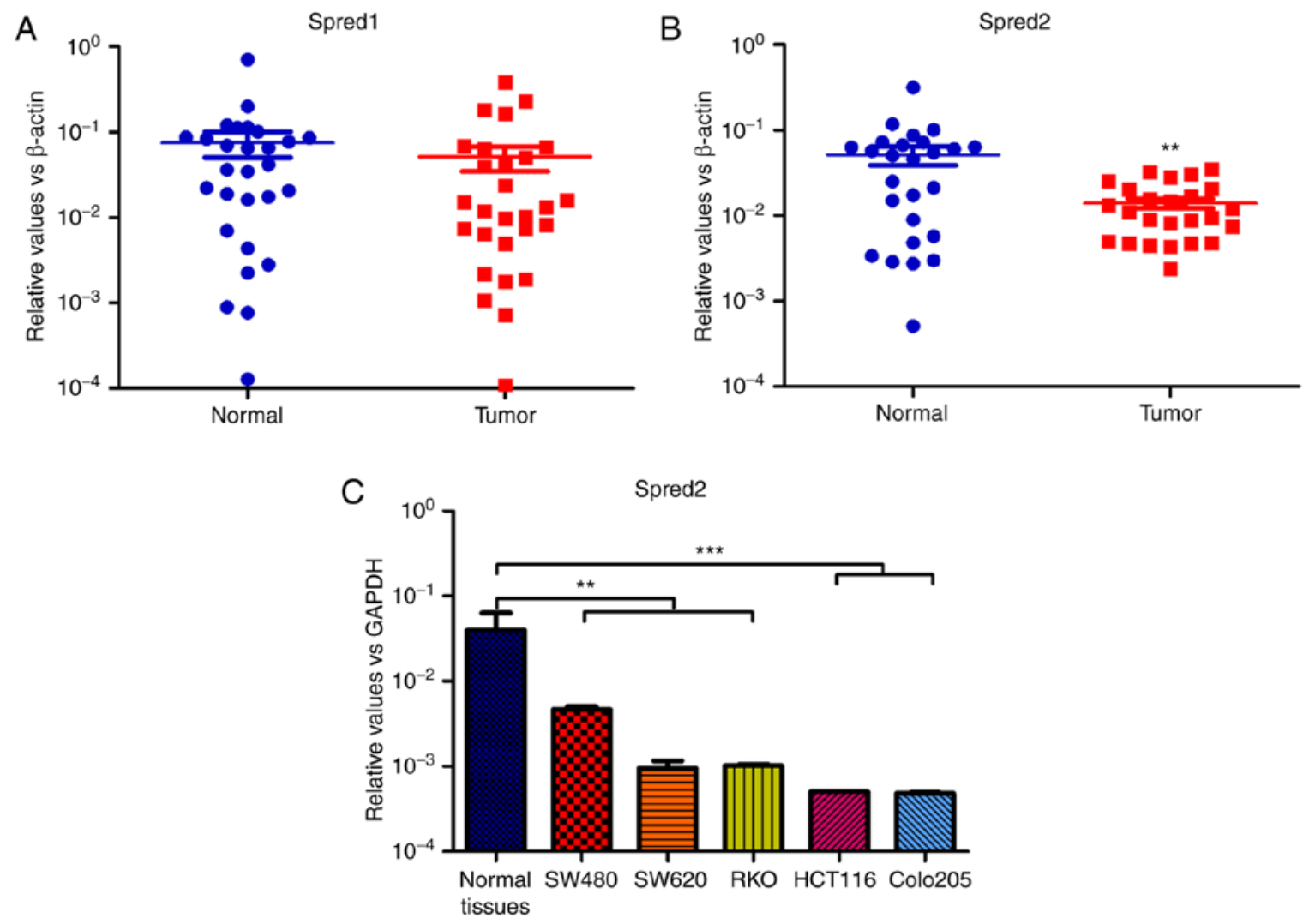

Figure 1. Spred1 and Spred2 expression in the tumor lesions of CRC patients. Surgical specimens were obtained from 26 CRC patients, and were divided into tumor tissues, paracancerous tissues and distal normal tissues according to the results of the clinical pathological examination. The total RNA was isolated from tumor lesions and corresponding distal normal tissues. After cDNA synthesis, the mRNA expression of (A) Spred1 and (B) Spred2 was detected by RT-PCR, and normalized to $\beta$-actin. Moreover, the mRNA expression in CRC cell lines and distal normal tissues aforementioned, was also detected by real-time RT-PCR, and, the relative expression level of Spred2 was normalized to GAPDH. (C) Data are presented as the mean \pm SEM. ${ }^{* * *} \mathrm{P}<0.01$ and ${ }^{* * * *} \mathrm{P}<0.001$, compared to the expression in corresponding normal tissues. Spred2, sprouty-related EVH1 domain protein 2; CRC, colorectal cancer; RT-PCR, real-time reverse transcription polymerase chain reaction.

decreased migration (Fig. 2E and F). These results indicated that Spred 2 is a pivotal molecule in modulating tumor growth, progression and metastasis.

Ad.Spred 2 inhibits the EMT of CRC cells in vitro. As aforementioned, Spred 2 significantly impaired the migratory ability of CRC cells in vitro. Therefore, the mechanisms involved in Spred 2 regulation of tumor metastasis, were explored. In SW480 and HCT116 cells, decreased filamentous actin (F-actin) expression and aggregation indicated that Spred2 may play pivotal roles in regulating EMT, an essential event during tumor metastasis to distant sites (Fig. 3A).

During EMT, cells lose epithelial markers, such as E-cadherin, but acquire mesenchymal markers, such as $\mathrm{N}$-cadherin and vimentin. In the present study, it was determined that Spred2 overexpression increased E-cadherin expression and decreased $\mathrm{N}$-cadherin and vimentin protein in SW480 cells (Fig. 3B and C). However, in HCT116 cells, Spred 2 only significantly downregulated the mesenchymal markers, N-cadherin and vimentin, but did not affect E-cadherin (Fig. 3D). The results indicated that Spred2 can impair EMT in CRC cells.

TGF- $\beta$ activates SMAD signaling and induces EMT in CRC cells. TGF- $\beta$, a multifunctional cytokine, can induce
EMT in tumor cells via both SMAD-dependent and SMAD-independent activation of EMT-related transcription factors $(21,22)$. Firstly, it was confirmed that $10 \mathrm{ng} / \mathrm{ml} \mathrm{TGF}-\beta$ could activate classic SMAD signaling in CRC cells. In fact, it enhanced the phosphorylation of SMAD2/3 and increased SMAD4 levels in SW480 cells (Fig. 4A).

Consistent with previous studies, it was demonstrated that TGF- $\beta$ treatment significantly enhanced the migration of SW480 cells (Fig. 4B) $(23,24)$. Then, the effects of TGF- $\beta$ on EMT were analyzed. Untreated SW480 cells exhibited a typical epithelial morphology, but TGF- $\beta$ treatment increased the number and percentage of fibroblast-like spindle-shaped cells. Moreover, rhodamine-phalloidin staining was used to show the distribution of F-actin, which has also emerged as an important marker of EMT in tumor cells. As expected, F-actin filaments showed a pericellular plasma membrane distribution in untreated SW480 cells. However, TGF- $\beta$ treatment enhanced rhodamine-phalloidin staining, and F-actin was assembled into thick parallel bundles (Fig. 4C). Furthermore, the expression of E-cadherin and vimentin was also analyzed. Notably, TGF- $\beta$ increased the protein expression of both vimentin and E-cadherin (Fig. 4D and E). It was hypothesized that the ratio of vimentin and E-cadherin, but not their absolute expression determines the EMT phenotype of tumor cells. 
A
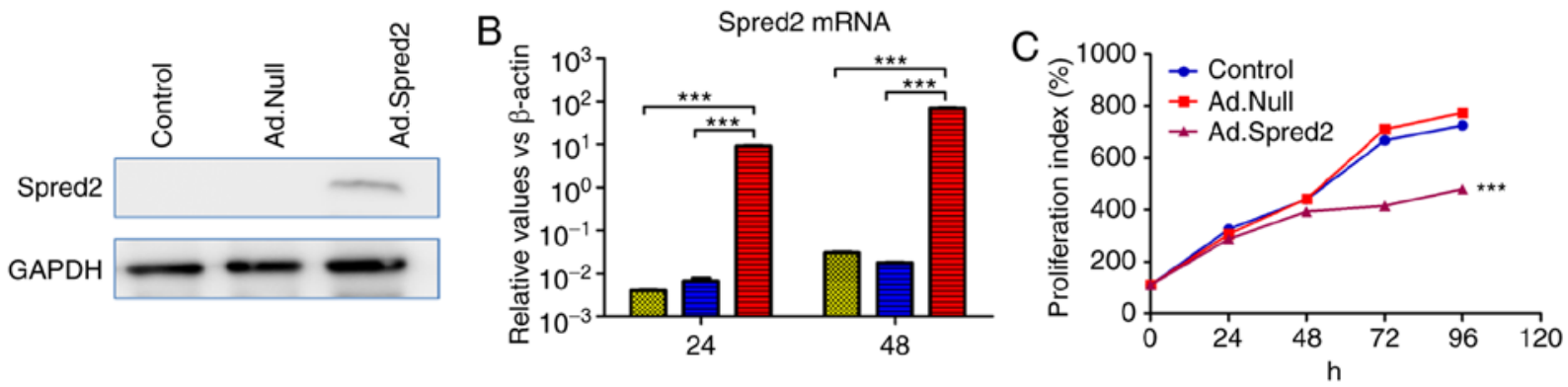

D
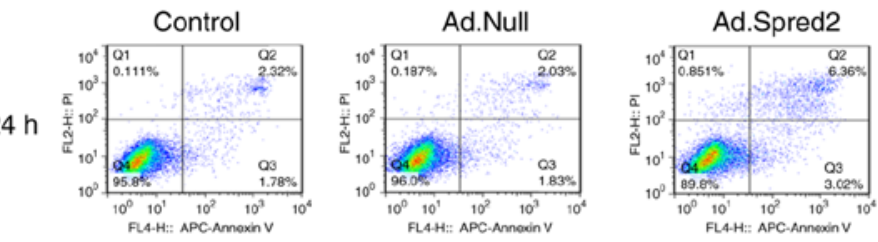

$48 \mathrm{~h}$
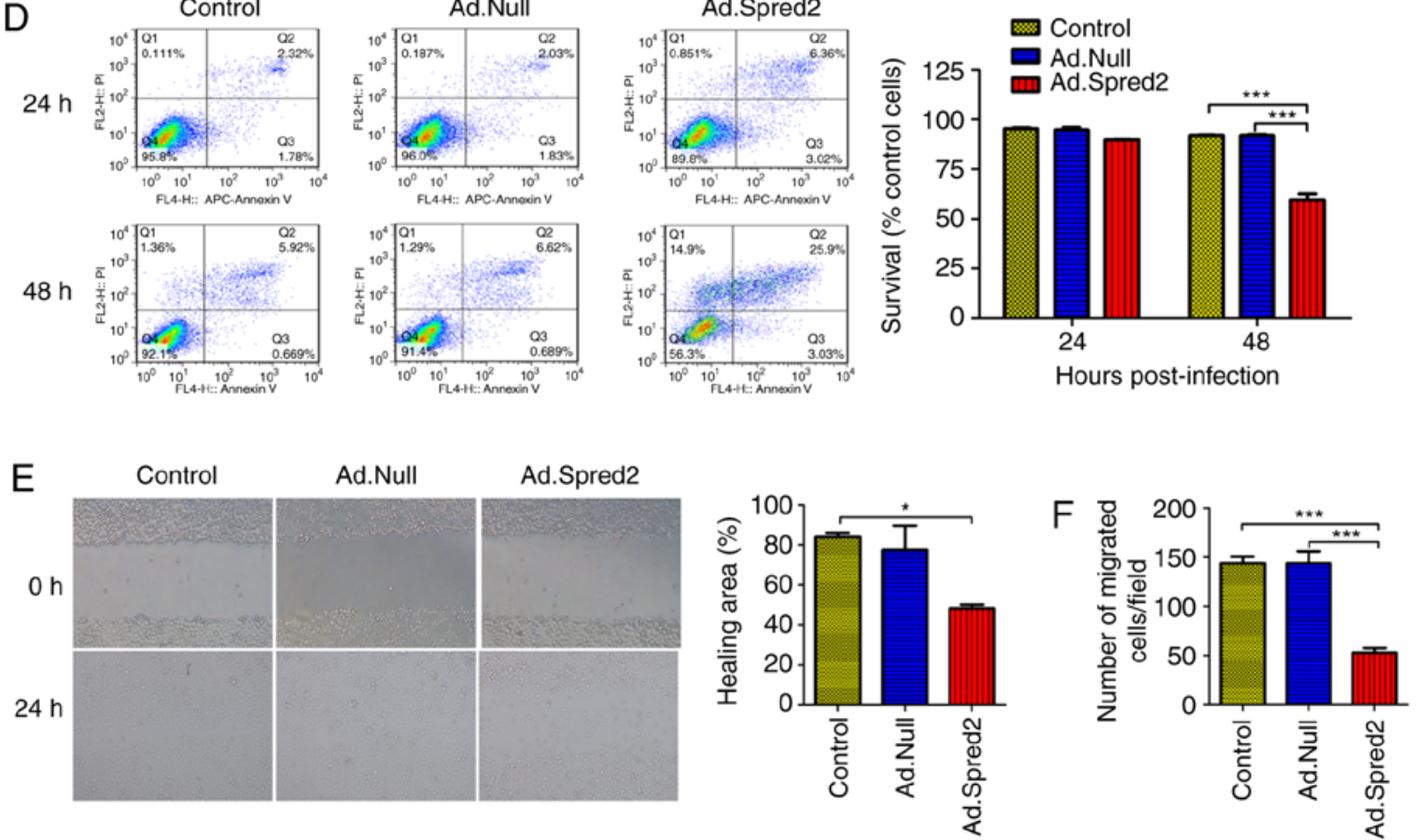

Figure 2. Ad.Spred2 transduction reduces proliferation, induces apoptosis and inhibits migration in SW480 cells. Exponentially growing SW480 cells were infected with Ad.Spred2, an adenoviral vector expressing Spred2, at an MOI of 50. (A and B) Ad.Spred2 mediated Spred2 protein and mRNA expression. (A) Forty-eight hours later, the cells were collected and Spred2 protein expression was analyzed by western blotting. (B) In addition, at 24 and $48 \mathrm{~h}$ after infection, Spred2 mRNA expression was also detected by real-time RT-PCR (B) (C-F) The effects of Spred2 on the biological characteristics of SW480 cells were analyzed. (C) Cellular proliferation at 24, 48, 72 and $96 \mathrm{~h}$ after infection was analyzed by flow cytometry using Fluor 670 dye staining. The relative proliferation index was calculated. (D) At 24 and $48 \mathrm{~h}$ after infection, cells were collected and labeled with Annexin V/APC and PI. Cellular apoptosis was analyzed by flow cytometry, and the survival rate was calculated. (E) Twenty-four hours after adenoviral infection, confluent SW480 cells were scratched to generate wounds, and the percentage of the wounded area filled was analyzed and is presented. (F) Furthermore, the migratory ability was also analyzed by Transwell assay, and the cells that passed through the membrane were counted. All the data were obtained from at least three independent experiments, and data in $\mathrm{B}-\mathrm{F}$ are presented as the mean $\pm \mathrm{SEM}$. ${ }^{*} \mathrm{P}<0.05$ and ${ }^{* * *} \mathrm{P}<0.001$, vs. the corresponding control group. Spred2, sprouty-related EVH1 domain protein 2.

Spred2 inhibits EMT in CRC cells in an ERK signaling-dependent manner. Spred2 is a negative regulator of growth factor-induced RAS-ERK activation. It was revealed that Spred 2 overexpression significantly inhibited the phosphorylation of ERK in SW480 cells (Fig. 5A). Then, ERK signaling was blocked by using a specific inhibitor, PD98059, and it was revealed that the level of phosphorylated ERK was significantly downregulated. Similar to Spred2, PD98059 increased E-cadherin expression, but reduced vimentin protein levels in SW480 cells (Fig. 5B), indicating that ERK signaling plays pivotal roles in regulating EMT in SW480 cells.

As aforementioned, the TGF- $\beta /$ SMAD signaling pathway plays important roles in regulating EMT in colon cancer cells. Therefore, it was investigated whether Spred 2 could block TGF- $/$ /SMAD signaling to inhibit EMT processes. SW480 cells were first treated with PD98059, and then stimulated with $10 \mathrm{ng} / \mathrm{ml}$ TGF- $\beta$. The expression of SMAD2/3 and
SMAD4, and the level of phosphorylated SMAD2/3 were not affected by PD98059 (Fig. 5C), which suggested that ERK signaling blockade can inhibit EMT in SW480 cells in a SMAD-independent manner. It was also demonstrated that Ad.Spred2 had no significant effect on the expression of SMADs (Fig. 5D). The results indicated that Spred2 inhibited EMT in SW480 cells by regulating ERK signaling, but not TGF- $\beta /$ SMAD signaling.

In HCT116 cells, phosphorylated ERK was also significantly downregulated by Ad.Spred 2 at $48 \mathrm{~h}$ after transduction (Fig. 6A). It was determined that neither PD98059 nor Ad.Spred2 had a marked effect on E-cadherin expression, but both reduced vimentin protein levels (Fig. 6B), suggesting that Spred2 reduced EMT in HCT116 cells by inhibiting ERK signaling. Moreover, SMAD2/3 and SMAD4 expression after treatment with Ad.Spred2 and PD98059 was also analyzed. Notably, Ad.Spred2 and PD98059 had opposite effects on the expression 

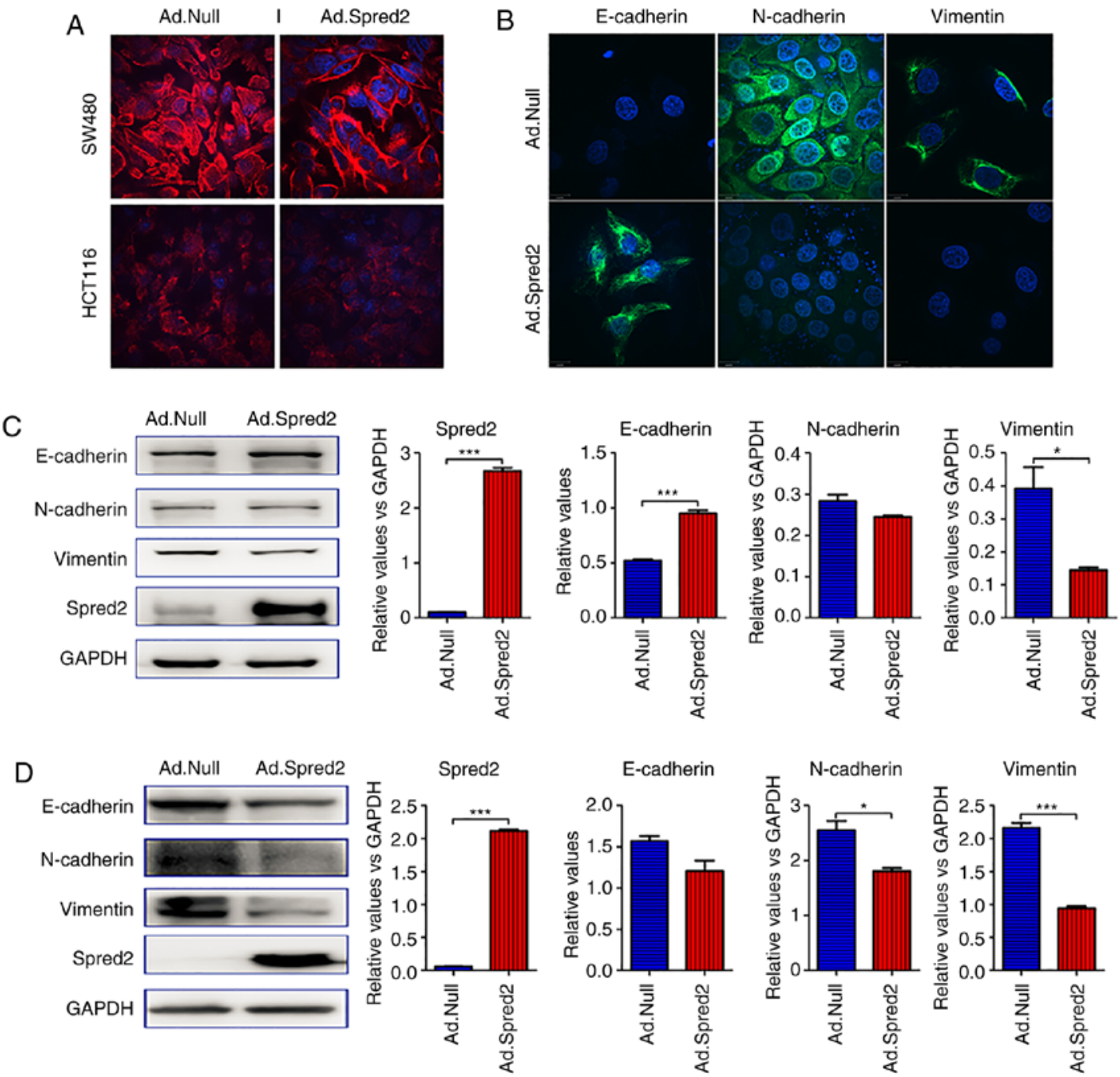

Figure 3. Ad.Spred2 inhibits EMT of CRC cells. (A) Exponentially growing SW480 cells and HCT116 cells were infected with Ad.Spred2 at an MOI of 50. At $48 \mathrm{~h}$ after infection, the expression and intercellular distribution of F-actin, an important indicator of EMT, was analyzed by rhodamine-phalloidin staining and observed by confocal microscopy. (B) Then, the protein expression and intercellular location of the epithelial marker E-cadherin, and mesenchymal markers N-cadherin and vimentin in SW480 cells were analyzed by immunofluorescence staining and observed by confocal microscopy. In addition, Spred2, E-cadherin, N-cadherin and vimentin protein expression in (C) SW480 cells and (D) HCT116 cells was also detected by western blotting. The results of semi-quantitative analysis are also presented in C and D. All the data were obtained from at least three independent experiments. Data in C and D are presented as the mean \pm SEM. ${ }^{*} \mathrm{P}<0.05$ and ${ }^{* * *} \mathrm{P}<0.001$, vs. Ad.Null-treated cells. Spred2, sprouty-related EVH1 domain protein 2; EMT, epithelial-mesenchymal transition; CRC, colorectal cancer.

of SMAD2/3 and SMAD4. PD98059 increased SMAD4 expression, while Ad.Spred 2 reduced SMAD2/3 and SMAD4 levels. These results indicated that Spred 2 regulated TGF- $\beta /$ SMAD signaling via an ERK signaling-independent manner. Unlike its roles in SW480 cells, Ad.Spred2 may also participate in the regulation of EMT by inhibiting TGF- $\beta$ signaling in HCT116 cells. Therefore, it was concluded that Ad.Spred2 can inhibit EMT in CRC cells in an ERK signaling-dependent manner.

\section{Discussion}

CRC is the fourth leading cause of cancer-related deaths worldwide, and there are still no effective approaches to treat advanced and metastatic CRC $(1,25,26)$. Exploring the mechanisms of CRC initiation and progression will be beneficial for discovering novel therapeutic targets. The Ras/Raf-1/ERK signaling pathway is always aberrantly activated in various tumors (27-30). Moreover, Spred1 and Spred2, two important members of the Spred family, are frequently downregulated in various cancers, such as hepatocellular carcinoma and prostate cancer (13). Notably, the protein level of Spred is closely associated with tumor progression and metastasis. In the present study, it was revealed that Spred2, but not Spred1, was markedly decreased in the tumor tissues of CRC patients and CRC cell lines. Moreover, Spred 2 restoration inhibited the proliferation, migration and survival of CRC cells. Notably, it was revealed that Spred 2 mRNA expression increased 5-10 times from 24 to $48 \mathrm{~h}$ after culture, in both control and rAd.Null-treated groups. Spred 2 is a natural inhibitor of ERK signaling, which plays important roles in regulating cellular apoptosis. Therefore, it was surmised that upregulation of Spred 2 at $48 \mathrm{~h}$ may be associated with cellular apoptosis caused by nutrient deficiencies after long-time culture. The investigation of the mechanisms is of interest for future studies. These results indicated that Spred 2 is a pivotal molecule in $\mathrm{CRC}$ development and progression. 

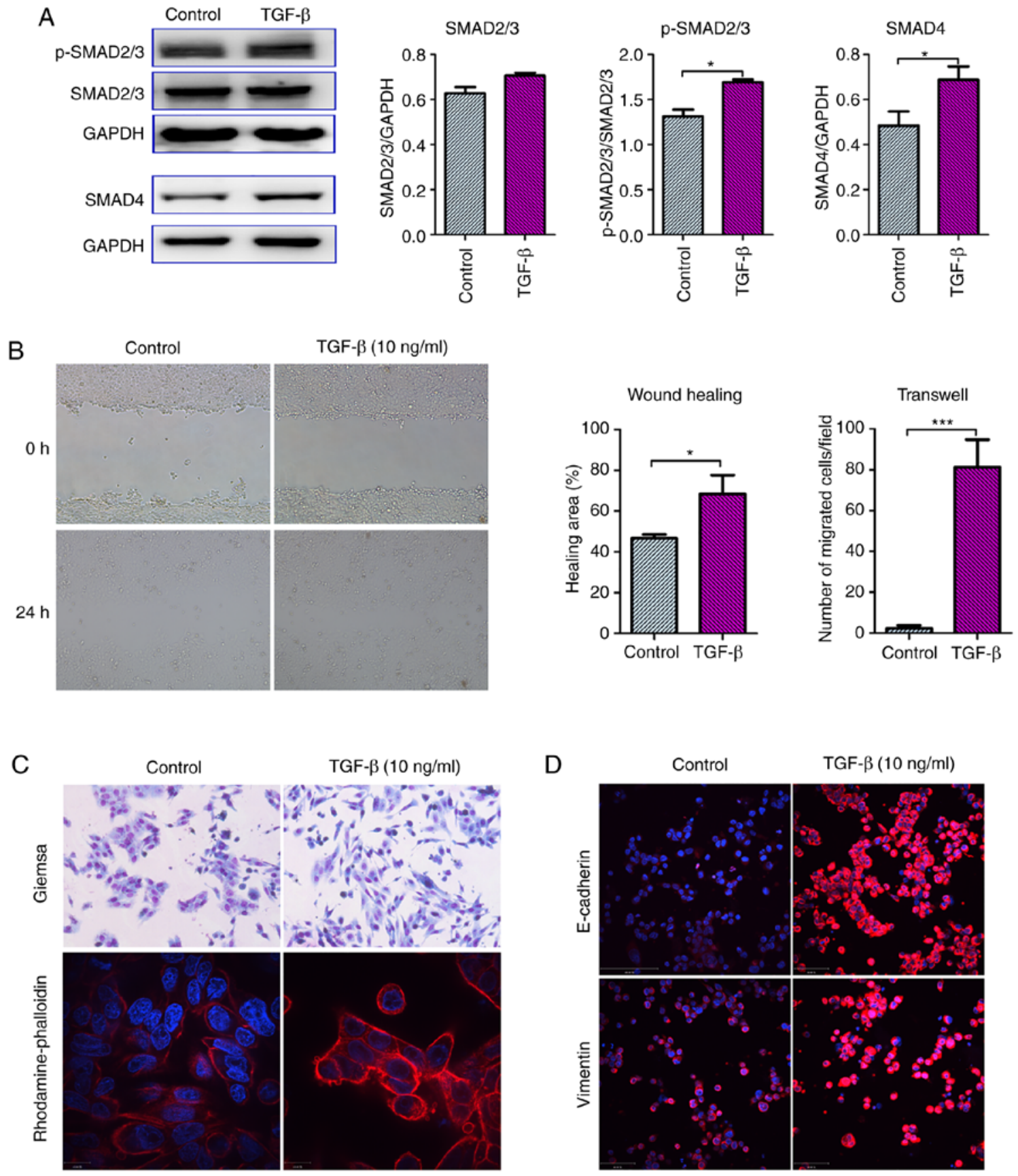

D
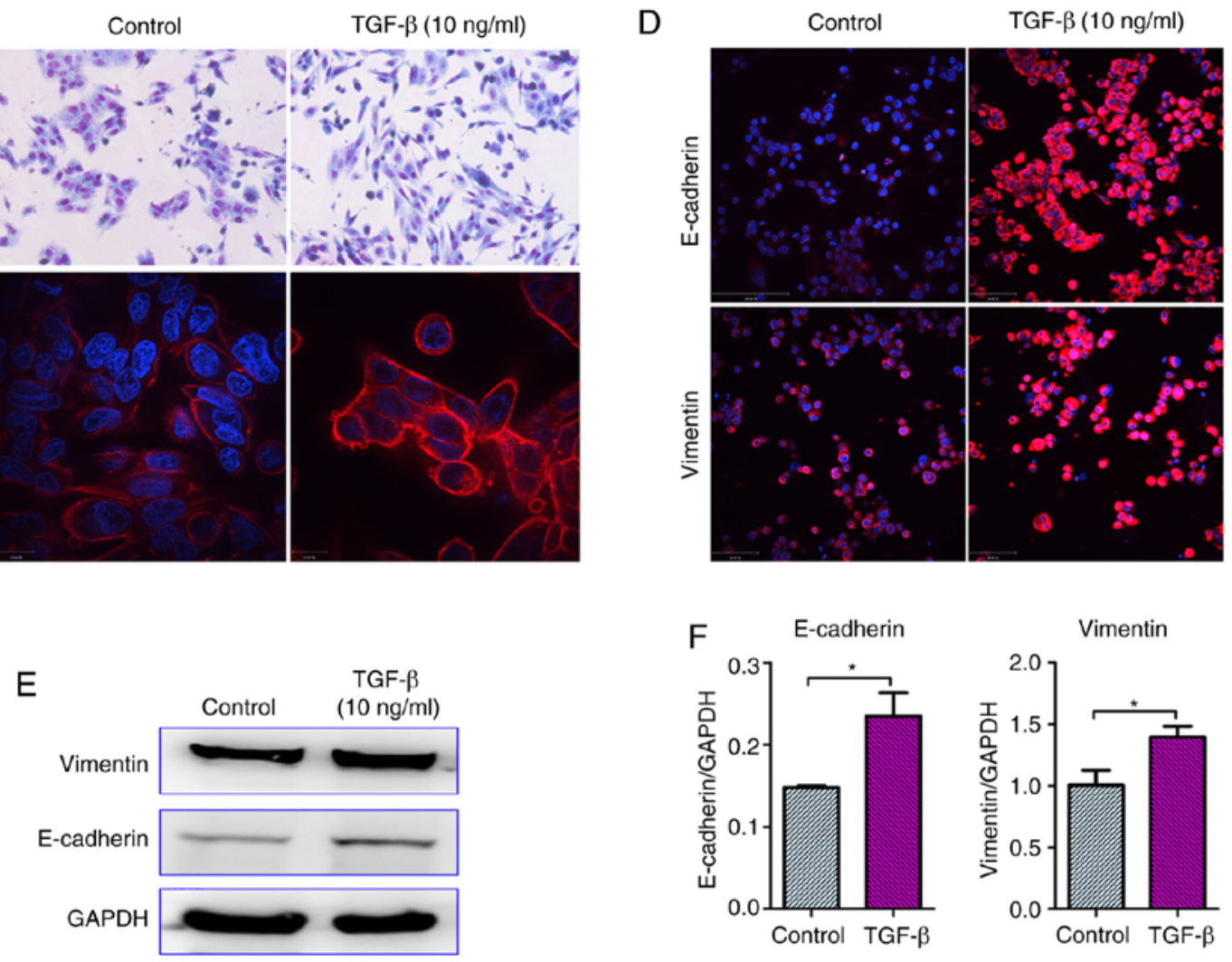

Figure 4. TGF- $\beta$ activates SMAD signaling and induces EMT in SW480 cells. Exponentially growing SW480 cells were stimulated with $10 \mathrm{ng} / \mathrm{ml}$ TGF- $\beta$. At $48 \mathrm{~h}$ after treatment, the expression of pivotal molecules in the SMAD signaling pathway, SMAD2/3, phosphorylated SMAD2/3 and SMAD4, was detected by western blotting. Representative images and the results of semi-quantitative analysis are presented in A. (B) The effects of TGF- $\beta$ on the migratory ability of SW480 cells were analyzed by wound healing and Transwell assays. For the wound healing assay, confluent SW480 cells were scratched to generate wounds and stimulated with $10 \mathrm{ng} / \mathrm{ml}$ TGF- $\beta$ for $24 \mathrm{~h}$. For the Transwell assay, $10 \mathrm{ng} / \mathrm{ml}$ TGF- $\beta$ was added in the lower compartment, while cells were seeded in the insert compartment. (C) The cellular morphology was observed after Giemsa staining, while the F-actin distribution was detected by rhodamine-phalloidin staining. Moreover, the expression of E-cadherin and vimentin was detected by (D) immunofluorescence staining and (E and F) western blotting and quantitative analysis. All the data were obtained from at least three independent experiments. Data in A, B and F are presented as the mean \pm SEM. "P $<0.05$ and ${ }^{* * * *} \mathrm{P}<0.001$, vs. the control (TGF- $\beta$ untreated cells). TGF- $\beta$, transforming growth factor- $\beta$; EMT, epithelial-mesenchymal transition. 
A

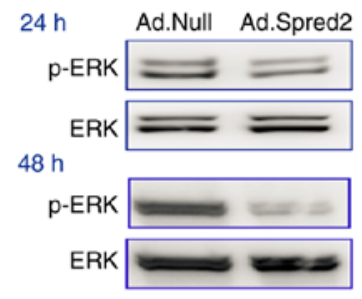

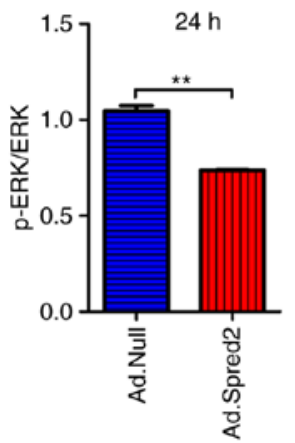

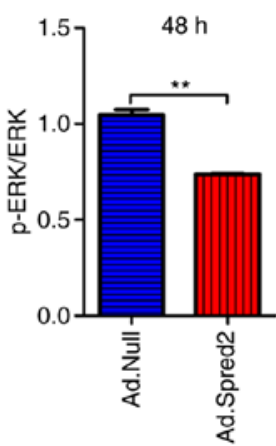

B

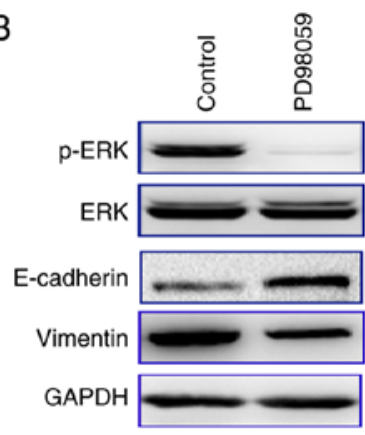

C

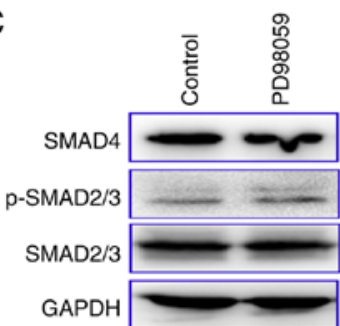

p-ERK

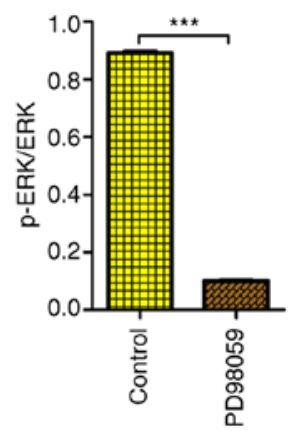

SMAD2/3

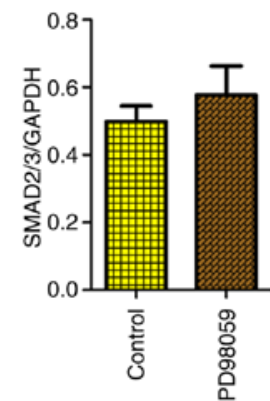

E-cadherin

Vimentin
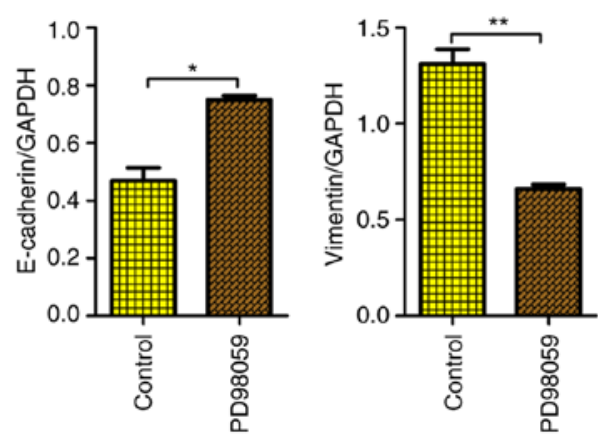

P-SMAD2/3/SMAD2/3

SMAD4
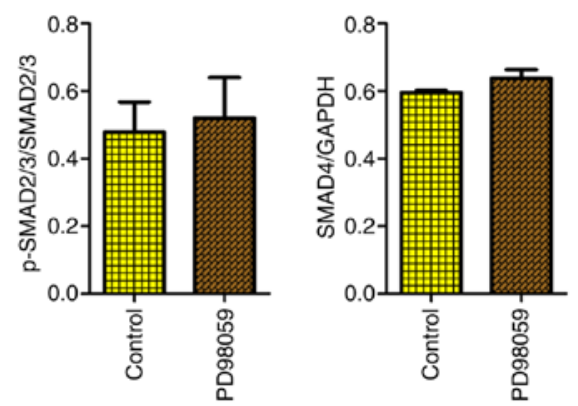
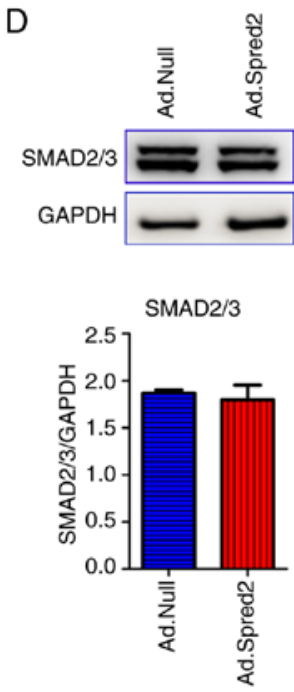

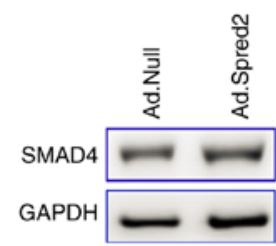

SMAD4

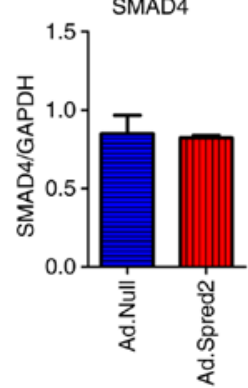

$24 \mathrm{~h}$ after infection
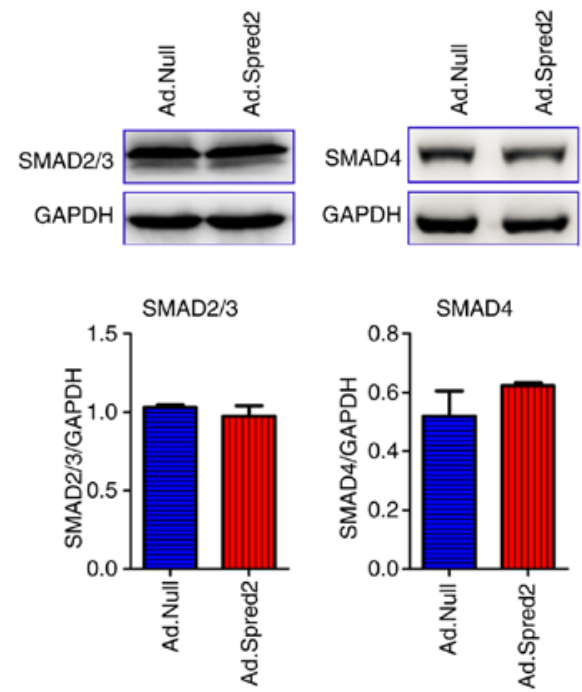

$48 \mathrm{~h}$ after infection

Figure 5. Ad.Spred2 impairs ERK signaling, but not SMAD signaling to inhibit EMT in SW480 cells. Exponentially growing SW480 cells were infected with Ad.Spred2 and Ad.Null at an MOI of 50. (A) Then, the phosphorylated ERK expression was detected at the indicated time-points and normalized to ERK expression. ERK specific inhibitor, PD98059, was used to inhibit ERK phosphorylation, which was confirmed by western blotting at $24 \mathrm{~h}$ after treatment. The (B) EMT markers, E-cadherin, N-cadherin and vimentin, and the (C) SMAD signaling molecules SMAD2/3, phosphorylated SMAD2/3 and SMAD4 were analyzed by western blotting $48 \mathrm{~h}$ after PD98059 treatment. (D) Moreover, the SMAD2/3 and SMAD4 protein expression was also analyzed $48 \mathrm{~h}$ after adenoviral transduction. All the data are obtained from at least three independent experiments, and presented as the mean $\pm \mathrm{SEM} .{ }^{*} \mathrm{P}<0.05,{ }^{* *} \mathrm{P}<0.01$ and ${ }^{* * * *} \mathrm{P}<0.001$, vs. the corresponding group. ERK, extracellular-regulated kinase; EMT, epithelial-mesenchymal transition. 
A

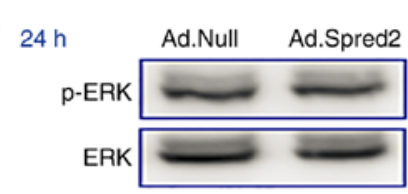

$48 \mathrm{~h}$

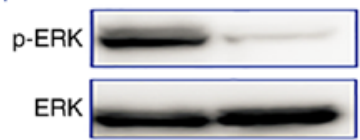

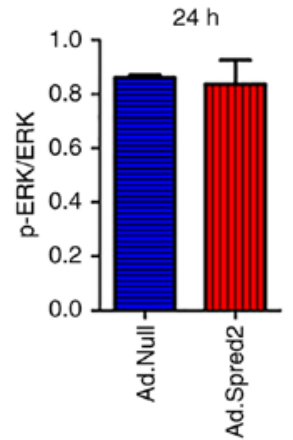

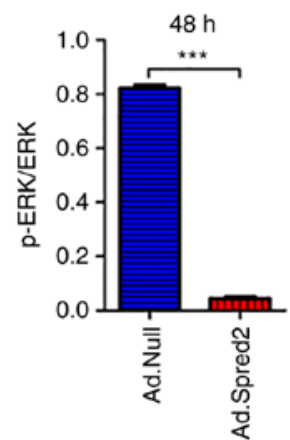

B
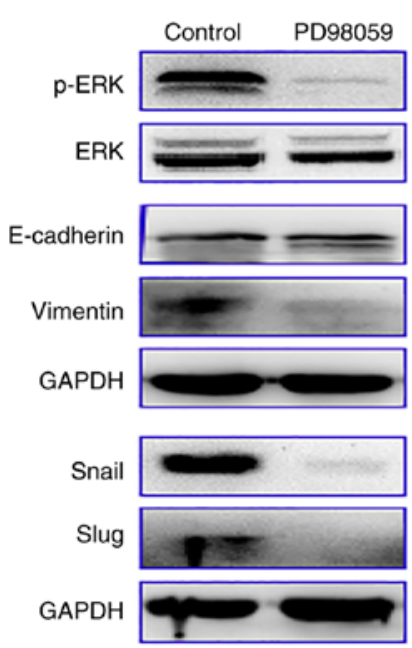
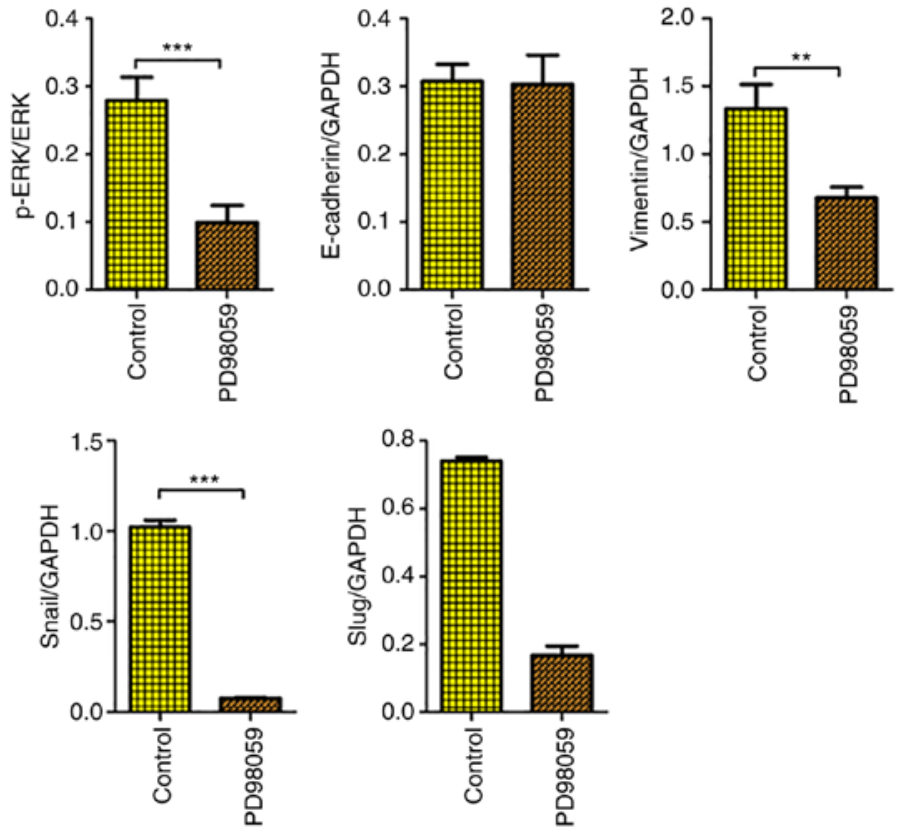

C

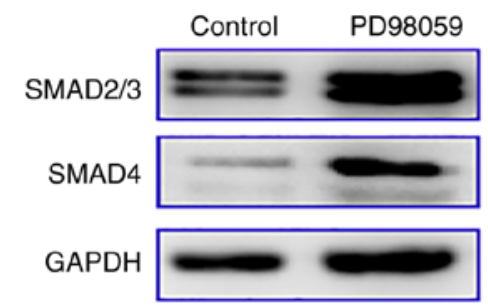

D
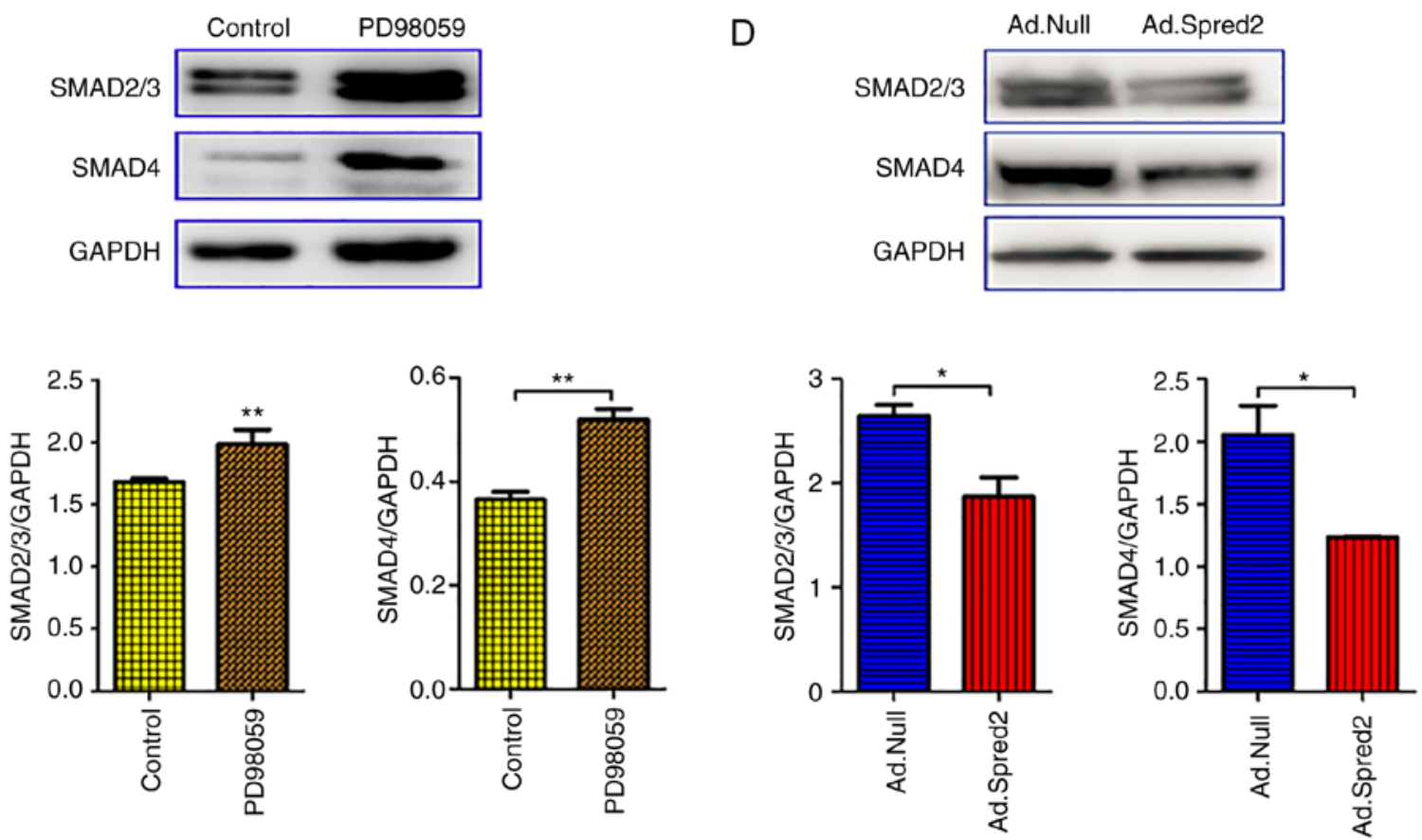

Figure 6. Ad.Spred2 impairs ERK signaling and SMAD signaling to inhibit EMT in HCT116 cells. (A) Exponentially growing HCT116 cells were infected by Ad.Spred2 or Ad.Null at an MOI of 50, and the ERK and phosphorylated ERK levels were detected at 24 and $48 \mathrm{~h}$ after adenoviral infection. (B) The phosphorylated ERK and ERK levels were analyzed at $24 \mathrm{~h}$ after PD98059 treatment. Moreover, the EMT markers E-cadherin, N-cadherin and Vimentin, and the EMT-related transcription factors Snail and Slug, were analyzed at $48 \mathrm{~h}$ after PD98059 treatment. In addition, at $48 \mathrm{~h}$ after the indicated treatments, the protein expression of SMAD2/3 and SMAD4 was analyzed in both (C) PD98059-treated cells and (D) adenoviruses-infected cells. All the data were obtained from at least three independent experiments, and are presented as the mean $\pm \mathrm{SEM} .{ }^{*} \mathrm{P}<0.05,{ }^{* *} \mathrm{P}<0.01,{ }^{* * *} \mathrm{P}<0.001$, vs. the corresponding group. ERK, extracellular-regulated kinase; EMT, epithelial-mesenchymal transition. 
EMT, which plays crucial roles in both embryonic development and tumor metastasis, is characterized by the loss of epithelial markers and acquisition of mesenchymal markers (31-33). TGF- $\beta$, a pleiotropic cytokine, is a pivotal molecule in the EMT processing of tumor cells and can activate EMT-related transcription factors in both SMAD-dependent and SMAD-independent manners $(21,22,34)$. It was confirmed that $10 \mathrm{ng} / \mathrm{ml}$ TGF- $\beta$ could activate SMAD signaling and increase cellular migration in CRC cells by promoting reorganization of the actin cytoskeleton and upregulating vimentin expression. However, the epithelial marker E-cadherin was also reduced by TGF- $\beta$. It was speculated that TGF- $\beta$ regulates the EMT of SW480 cells by modulating the ratio of mesenchymal markers to epithelial markers, but not their absolute expression.

Spred proteins negatively regulate TGF $\beta$-induced EMT (35-36). In keratinocytes, Spred2 was revealed to inhibit TGF $\beta$-induced EMT by restoring E-cadherin levels, reducing vimentin expression, and preventing reorganization of the actin cytoskeleton. Ad.Spred2-mediated Spred2 overexpression significantly inhibited EMT in both SW480 and HCT116 cells. In addition, Ad.Spred2 both increased E-cadherin levels and reduced vimentin levels in SW480 cells, however, it only decreased mesenchymal markers in HCT116 cells. It was speculated that Ad.Spred2 regulated EMT in CRC cells with various genetic backgrounds in different ways. Combining immunofluorescence and confocal microscopy is a widely used tool to analyze the expression and distribution of proteins. In the present study, E-cadherin and vimentin expression was detected by immunofluorescence in SW480 cells, but not in HCT116 cells. To further clarify the mechanisms underlying Spred2-regulated EMT, the distribution of EMT markers will be investigated in CRC cells with various genetic backgrounds. Notably, it was revealed that SMAD2/3 and SMAD4 expression was downregulated by Ad.Spred 2 in HCT116 cells but not in SW480 cells, which may be attributed to the different regulatory mechanisms of various tumor cells. However, the mechanisms underlying these different responses to Ad.Spred2 were not investigated in this study. The distinct sensitivity of CRCs to TGF- $\beta$ may be a reason for these discrepancies. Therefore, study of the effects of treatment with TGF- $\beta$ at various doses will be necessary to clarify the exact mechanisms. Data from our studies and others have suggested that Spred2 is a negative regulator of EMT in epithelial cells, including normal and tumor cells $(14,35,36)$. However, the roles of Spred2 in mesenchymal cells are still largely unexplored. Notably, investigation of whether Spred2 regulates mesenchymal-epithelial transition (MET) in human mesenchymal stem cells is of great interest.

Numerous studies have demonstrated that mitogen-activated protein kinase (MAPK)/ERK signaling participates in multiple cellular processes during tumor progression and metastasis, including growth, proliferation, differentiation and migration (7,8,28-30). Notably, aberrant activation of MAPK/ERK signaling is always closely associated with the EMT of tumor cells in various cancers. In CRC cells, the carboxyl terminus of Hsc70-interacting protein (CHIP) was revealed to promote tumor metastasis by activating MAPK signaling and reducing E-cadherin expression (37). Moreover, miR-27b could induce EMT in gastric cancer by inhibiting Sprouty2, which plays a suppressive role in the MAPK/ERK signaling pathway (38). Spred2, another important negative regulator of MAPK/ERK signaling, could markedly inhibit the level of phosphorylated ERK in CRC cells. Further analysis revealed that Ad.Spred2 and the ERK-specific inhibitor, PD98059, had similar effects on the expression of EMT markers in both SW480 cells and HCT116 cells. These results indicated that ERK signaling inhibition is a pivotal mechanism underlying Spred2-mediated impairment of EMT in CRC cells. Furthermore, neither Ad.Spred2 nor PD98059 could regulate SMAD2/3 and SMAD4 levels in SW480 cells, indicating that Spred 2 modulates EMT in a SMAD-independent manner. However, Ad.Spred2 reduced intercellular SMAD2/3 and SMAD4 levels, while PD98059 increased SMAD4 expression in HCT116 cells. It was speculated that Ad.Spred2 can inhibit SMAD signaling in an ERK signaling-independent manner. Therefore, Ad.Spred 2 may regulate EMT in both SMAD-dependent and SMAD-independent manners.

In conclusion, the expression of negative regulator of MAPK/ERK signaling, Spred2, was markedly downregulated in the tumor tissues of CRC patients. In vitro restoration of Spred2 significantly inhibited the growth, survival and migration of CRC cells. Moreover, Spred 2 could inhibit the migration of tumor cells by impairing the EMT of CRC cells, as it downregulated E-cadherin and upregulated vimentin. Furthermore, Ad.Spred2 inhibited EMT by impairing ERK signaling, with or without reduced TGF- $3 /$ SMAD signaling (Fig. S1). Therefore, the introduction of the clinical application of Spred2 has great potential for development as a gene therapy approach for CRC.

\section{Acknowledgements}

We are thankful to the National Clinical Research Center for Digestive Disease, Department of General Surgery, Beijing Friendship Hospital for providing clinical samples in this study.

\section{Funding}

The present study was supported by the National Natural Science Foundation of China (no. 81402558\&81472396), and the National High Technology Research and Development Program of China (863 Program) (SS2014AA020515). These funding agencies had no role in the study design, data collection and analysis, decision to publish, or preparation of the manuscript.

\section{Availability of data and materials}

All data generated or analyzed during this study are included in this published article.

\section{Authors' contributions}

SL and LW conceived and designed the experiments. HW, FK, FX, YL, SZ and DH performed the experiments. HW and YY analyzed the data. FX contributed to the collection of reagents/materials/analytical tools. YY wrote the paper. All authors read and approved the manuscript and agree to be accountable for all aspects of the research in ensuring that the accuracy or integrity of any part of the work are appropriately investigated and resolved. 


\section{Ethics approval and consent to participate}

All the procedures were approved by the Ethics Committee of Beijing Friendship Hospital. All patients provided written informed consent.

\section{Patient consent for publication}

Not applicable.

\section{Competing interests}

The authors declare that they have no competing interests.

\section{References}

1. Bray F, Ferlay J, Soerjomataram I, Siegel RL, Torre LA and Jemal A: Global cancer statistics 2018: GLOBOCAN estimates of incidence and mortality worldwide for 36 cancers in 185 countries. CA Cancer J Clin 68: 394-424, 2018.

2. Siegel RL, Miller KD, Fedewa SA, Ahnen DJ, Meester RGS, Barzi A and Jemal A: Colorectal cancer statistics, 2017. CA Cancer J Clin 67: 177-193, 2017.

3. Gonzalez-Pons M and Cruz-Correa M: Colorectal cancer biomarkers: Where are we now? Biomed Res Int 2015: 149014, 2015.

4. Brenner H, Stock C and Hoffmeister M: Colorectal cancer screening: The time to act is now. BMC Med 13: 262, 2015.

5. Wrobel P and Ahmed S: Current status of immunotherapy in metastatic colorectal cancer. Int J Colorectal Dis 34: 13-25, 2019.

6. Van der Jeught K, Xu HC, Li YJ, Lu XB and Ji G: Drug resistance and new therapies in colorectal cancer. World J Gastroenterol 24 3834-3848, 2018.

7. Li Y, Zhang M, Dorfman RG, Pan Y, Tang D, Xu L, Zhao Z, Zhou Q, Zhou L, Wang Y, et al: SIRT2 promotes the migration and invasion of gastric cancer through RAS/ERK/JNK/MMP-9 pathway by increasing PEPCK1-related metabolism. Neoplasia 20 : 745-756, 2018

8. Qiu XY, Hu DX, Chen WQ, Chen RQ, Qian SR, Li CY, Li YJ, Xiong XX, Liu D, Pan F, et al: PD-L1 confers glioblastoma multiforme malignancy via Ras binding and Ras/Erk/EMT activation. Biochim Biophys Acta Mol Basis Dis 1864: 1754-1769, 2018.

9. Wu D, Zhao B, Qi X, Peng F, Fu H, Chi X, Miao QR and Shao S: Nogo-B receptor promotes epithelial-mesenchymal transition in non-small cell lung cancer cells through the Ras/ERK/Snail1 pathway. Cancer Lett 418: 135-146, 2018.

10. Hu YC, Wang AM, Lu JK, Cen R and Liu LL: Long noncoding RNA HOXD-AS1 regulates proliferation of cervical cancer cells by activating Ras/ERK signaling pathway. Eur Rev Med Pharmacol Sci 21: 5049-5055, 2017.

11. Wakioka T, Sasaki A, Kato R, Shouda T, Matsumoto A, MiyoshiK, Tsuneoka M, Komiya S, Baron R and Yoshimura A: Spred is a sprouty-related suppressor of ras signalling. Nature 412: 647-651, 2001.

12. Nobuhisa I, Kato R, Inoue H, Takizawa M, Okita K, Yoshimura A and Taga T: Spred-2 suppresses aorta-gonad-mesonephros hematopoiesis by inhibiting MAP kinase activation. J Exp Med 199: 737-742, 2004.

13. Kachroo N, Valencia T, Warren AY and Gnanapragasam VJ: Evidence for downregulation of the negative regulator SPRED2 in clinical prostate cancer. Br J Cancer 108: 597-601, 2013.

14. Ma XN, Liu XY, Yang YF, Xiao FJ, Li QF, Yan J, Zhang QW, Wang LS, Li XY and Wang H: Regulation of human hepatocellular carcinoma cells by Spred2 and correlative studies on its mechanism. Biochem Biophys Res Commun 410: 803-808, 2011.

15. Momeny M, Khorramizadeh MR, Ghaffari SH, Yousefi M, Yekaninejad MS, Esmaeili R, Jahanshiri Z and Nooridaloii MR: Effects of silibinin on cell growth and invasive properties of a human hepatocellular carcinoma cell line, HepG-2, through inhibition of extracellular signal-regulated kinase $1 / 2$ phosphorylation. Eur J Pharmacol 591: 13-20, 2008.

16. YoshidaT,Hisamoto T,Akiba J,KogaH,Nakamura K, Tokunaga Y, Hanada S, Kumemura H, Maeyama M, Harada M, et al: Spreds, inhibitors of the Ras/ERK signal transduction, are dysregulated in human hepatocellular carcinoma and linked to the malignant phenotype of tumors. Oncogene 25: 6056-6066, 2006.
17. Liu XY, Yang YF, Wu CT, Xiao FJ, Zhang QW, Ma XN, Li QF, Yan J, Wang H and Wang LS: Spred2 is involved in imatinib-induced cytotoxicity in chronic myeloid leukemia cells. Biochem Biophys Res Commun 393: 637-642, 2010.

18. Lu ZZ, Ni F, Hu ZB, Wang L, Wang H, Zhang QW, Huang WR, Wu CT and Wang LS: Efficient gene transfer into hematopoietic cells by a retargeting adenoviral vector system with a chimeric fiber of adenovirus serotype 5 and 11p. Exp Hematol 34: 1171-1182, 2006.

19. Xu W, Neill T, Yang Y, Hu Z, Cleveland E, Wu Y, Hutten R, Xiao X, Stock SR, Shevrin D, et al: The systemic delivery of an oncolytic adenovirus expressing decorin inhibits bone metastasis in a mouse model of human prostate cancer. Gene Ther 22: 247-256, 2015.

20. Livak KJ and Schmittgen TD: Analysis of relative gene expression data using real-time quantitative PCR and the 2(-Delta Delta C(T)) method. Methods 25: 402-408, 2001.

21. Huang Y, Li G, Wang K, Mu Z, Xie Q, Qu H, Lv H and Hu B: Collagen type VI alpha 3 chain promotes epithelial-mesenchymal transition in bladder cancer cells via transforming growth factor $\beta$ (TGF- $\beta$ )/Smad pathway. Med Sci Monit 24: 5346-5354, 2018.

22. Thakur AK, Nigri J, Lac S, Leca J, Bressy C, Berthezene P, Bartholin L, Chan P, Calvo E, Iovanna JL, et al: TAp73 loss favors Smad-independent TGF- $\beta$ signaling that drives EMT in pancreatic ductal adenocarcinoma. Cell Death Differ 23: 1358-1370, 2016.

23. Han S, Bui NT, Ho MT, Kim YM, Cho $M$ and Shin DB: Dexamethasone inhibits TGF- $\beta 1$-induced cell migration by regulating the ERK and AKT pathways in human colon cancer cells via CYR61. Cancer Res Treat 48: 1141-1153, 2016.

24. Lampropoulos P, Zizi-Sermpetzoglou A, Rizos S, Kostakis A, Nikiteas $\mathrm{N}$ and Papavassiliou AG: TGF- $\beta$ signalling in colon carcinogenesis. Cancer Lett 314: 1-7, 2012.

25. Elez E, Argiles G and Tabernero J: First-line treatment of metastatic colorectal cancer: Interpreting FIRE-3, PEAK, and CALGB/SWOG 80405. Curr Treat Options Oncol 16: 52, 2015.

26. Fakih MG: Metastatic colorectal cancer: Current state and future directions. J Clin Oncol 33: 1809-1824, 2015.

27. Cakir M and Grossman AB: Targeting MAPK (Ras/ERK) and PI3K/Akt pathways in pituitary tumorigenesis. Expert Opin Ther Targets 13: 1121-1134, 2009.

28. Khavari TA and Rinn J: Ras/Erk MAPK signaling in epidermal homeostasis and neoplasia. Cell Cycle 6: 2928-2931, 2007.

29. Torii S, Yamamoto T, Tsuchiya Y and Nishida E: ERK MAP kinase in G cell cycle progression and cancer. Cancer Sci 97: 697-702, 2006.

30. Samatar AA and Poulikakos PI: Targeting RAS-ERK signalling in cancer: Promises and challenges. Nat Rev Drug Discovery 13: 928-942, 2014.

31. Pastushenko I and Blanpain C: EMT transition states during tumor progression and metastasis. Trends Cell Biol 29: 212-226, 2019.

32. Chen T, You Y, Jiang H and Wang ZZ: Epithelial-mesenchymal transition (EMT): A biological process in the development, stem cell differentiation, and tumorigenesis. J Cell Physiol 232: 3261-3272, 2017.

33. Kim DH, Xing T, Yang Z, Dudek R, Lu Q and Chen YH: Epithelial mesenchymal transition in embryonic development, tissue repair and cancer: A comprehensive overview. J Clin Med 7: E1, 2017.

34. Tan QY and Cheng ZS: TGF $\beta 1$-smad signaling pathway participates in interleukin-33 induced epithelial-to-mesenchymal transition of A549 cells. Cell Physiol Biochem 50: 757-767, 2018.

35. Zhao G, Wojciechowski MC, Jee S, Boros J, McAvoy JW and Lovicu FJ: Negative regulation of TGF $\beta$-induced lens epithelial to mesenchymal transition (EMT) by RTK antagonists. Exp Eye Res 132: 9-16, 2015

36. Villar V, Kocic J and Santibanez JF: Spred2 inhibits TGF-beta1-induced urokinase type plasminogen activator expression, cell motility and epithelial mesenchymal transition. Int J Cancer 127: 77-85, 2010.

37. Xu J, Zhou J, Dai H, Liu F, Li W, Wang W and Guo F: CHIP functions as an oncogene by promoting colorectal cancer metastasis via activation of MAPK and AKT signaling and suppression of E-cadherin. J Transl Med 16: 169, 2018.

38. Jiang J, Yi B, Qin C, Ding S and Cao W: Upregulation of microRNA27b contributes to the migration and invasion of gastric cancer cells via the inhibition of sprouty2-mediated ERK signaling. Mol Med Rep 13: 2267-2272, 2016.

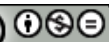

This work is licensed under a Creative Commons Attribution-NonCommercial-NoDerivatives 4.0 International (CC BY-NC-ND 4.0) License. 